\title{
A Flat Sagittal Spinal Alignment Is Common among Young Patients with Lumbar Disc Herniation
}

\author{
Olof Thoreson, Joel Beck, Klas Halldin, Helena Brisby, Adad Baranto \\ Department of Orthopaedics, Institute of Clinical Sciences at Sahlgrenska Academy, University of Gothenburg and Sahlgrenska \\ University Hospital, Gothenburg, Sweden \\ Email: olof.thoreson@vgregion.se
}

How to cite this paper: Thoreson, O., Beck, J., Halldin, K., Brisby, H. and Baranto, A. (2016) A Flat Sagittal Spinal Alignment Is Common among Young Patients with Lumbar Disc Herniation. Open Journal of Orthopedics, 6, 294-304.

http://dx.doi.org/10.4236/ojo.2016.69038

Received: August 10, 2016

Accepted: September 24, 2016

Published: September 27, 2016

Copyright $\odot 2016$ by authors and Scientific Research Publishing Inc. This work is licensed under the Creative Commons Attribution International License (CC BY 4.0).

http://creativecommons.org/licenses/by/4.0/

\begin{abstract}
Background: Recent studies suggest a correlation between spinal sagittal alignment and different types of lumbar pathologies due to different load patterns on the lumbar spine. The main objective of this study was to investigate the preoperative spinal sagittal alignment in young patients ( $<25$ years) undergoing lumbar disc herniation surgery. Methods: Information regarding preoperative clinical examinations was collected from the patient medical charts. Preoperative MRI examinations were used to classify lumbar types according to four sagittal spinal alignment groups (1: a long thoracic kyphosis, 2: a flat back, 3: a normal spine and 4: an increased thoracic kyphosis). Other MRI findings were also noted. Classification of lumbar types was performed independently by three spine surgeons. To compare two sample proportions the 2-sample z-test was performed. Results: The distribution of lumbar curve types was: Type 1,17\% (9 patients); Type 2, 62\% (33 patients); Type 3, 17\% (9 patients) and Type 4, 4\% (2 patients). The distribution of operated levels was: L3 - L4, 2\% (1 patient); L4 - L5, 47\% (25 patients); L5 - S1, 42\% (22 patients) and L4 - L5 + L5 - S1, 9\% (5 patients). Conclusions: A majority of the young patients (62\%) that underwent surgery due to herniated disc in the lumbar spine were classified as Type 2 indicating a flat back. Future studies are needed to increase the knowledge about spinopelvic sagittal alignment and the correlation to spinal pathologies.
\end{abstract}

\section{Keywords}

Intervertebral Disc Displacement, Sagittal Alignment, Spine, Surgery, Young Adult

\section{Introduction}

Several studies have suggested an association between certain pathologies in the spine, especially the lumbar spine, and an individual's spinal sagittal alignment. This is due to 
that different spinal alignments have differences in the loading of the distal lumbar segments [1]-[7]. However, there is a large normal variation in spinal alignments between asymptomatic individuals [8].

The sagittal alignment of the thoraco-lumbar spine is highly regulated by pelvic parameters. Boulay et al. [9] have suggested an equation to predict Lumbar Lordosis (LL) based on the pelvic parameters. The sagittal alignment can be regulated and altered in two regions, overlying state (kyphosis, T9 tilt) and underlying state (Sacral Slope, SS, Pelvic Tilt, PT). Pelvic Incidence (PI) is well defined by several studies [9] [10] and is determined by SS and PT and is the only parameter that is non-positional and constant. Boulay et al. [9] showed that low PI $\left(<44^{\circ}\right)$ correlates to low SS and flat lumbar lordosis, and high PI $\left(>62^{\circ}\right)$ correlates to a more pronounced lordosis and a steeper SS.

The normal sagittal alignment in a healthy paediatric population has been reported in many studies [11]-[14]. Mac-Thiong et al. [13] showed that PI regulates SS in children and adolescents in the same way as in adults. The study involved 341 healthy children and adolescents of both genders of 3 - 18 years of age, and the mean SS was $41.4^{\circ}\left( \pm 8.2^{\circ}\right)$. Additionally, Mac-Thiong et al. [14] reported that the mean SS for 479 asymptomatic adolescents of both sexes of 10 - 18 years of age was somewhat smaller, $39.1^{\circ}\left( \pm 7.6^{\circ}\right)$.

Roussouly et al. [15] have established a classification system describing the normal variation in sagittal alignment of the human lumbar spine and pelvis. This classification is a system where the spine is evaluated by full-length radiographs of the spine in the antero-posterior and lateral planes, extending from the base of the scull to the proximal femora in erect position. The classification identifies 4 types of spine curves. Type 1 has a long thoraco-lumbar kyphosis and a short hyperextended lordosis. Type 2 has a flat thoracic kyphosis and a flat lumbar lordosis. Type 3 has what is considered as a normal spine alignment-a moderate thoracic kyphosis and a moderate lumbar lordosis. Type 4 has an increased thoracic kyphosis and an increased lumbar lordosis (Figure 1). The

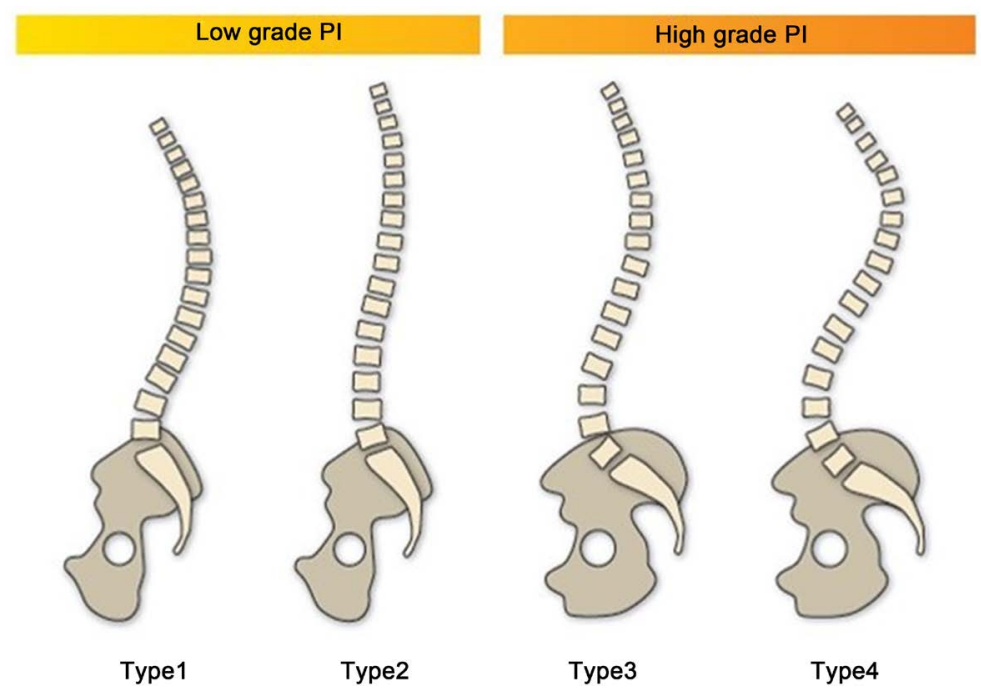

Figure 1. Roussouly Type 1 - 4 drawing. Drawing of the four different normal types of sagittal alignment of the human spine and pelvis: Type 1 and 2 have low grade of PI and Type 3 and 4 have high grade of PI. 
normal variation of the sagittal alignment of the lumbar spine has been determined by an examination of 160 volunteers (mean age 30.8 years) with no history of back pain. In this group, 34 persons ( $21 \%$ ) had a Type 1 alignment, 18 persons (11\%) had a Type 2 alignment, 60 persons (38\%) had Type 3 alignment and 48 persons (30\%) had a Type 4 alignment.

Roussouly and Pinheiro-Franco [1] described each of the four Roussouly types to be linked to specific pathologies. The Type 1 spine is suggested to have an increased risk of disc degeneration in the thoraco-lumbar kyphosis area. Further, in the kypho-lordotic junction area the discs are tilted with a greater risk of retrolisthesis. Type 2, which is the flat back, has a horizontal disc orientation. This is suggested to cause increased disc pressure with a higher risk of early disc degeneration and central disc herniations. This correlation is supported by publications such as Rajnics et al. [4], Barrey et al. [16] and Endo et al. [17]. Endo et al. [17] compared spinal alignment in healthy controls with patients that underwent surgery due to disc herniation. The results displayed less LL and SS, indicating a more flat back, in the disc herniation group compared to the control group. According to Roussouly and Pinheiro-Franco [1] the sagittal normal spine in Type 3 has not been linked to any certain pathological conditions. The Type 4 spine with its hyperlordotic lumbar curve is believed to cause increased force on the posterior elements where the disk plane is tilted forward. This may cause higher stress on the facet joints and thereby increase the risk of a fracture or elongation of the pars interarticularis area and spondylolisthesis (ventrolisthesis). This is supported by Marty et al. [5] that showed that a group of patients with spondylolisthesis had a larger angle of PI and SS than the normal population. In accordance with this, Labelle et al. [3] presented a cohort consisting of 214 patients with spondylolisthesis who had significantly greater lumbar lordosis, PI and SS, compared to a control population. Furthermore in Type 4, retrolisthesis is created where the intervertebral disc is tilted posteriorly.

The main objective of this retrospective cross sectional study was to investigate the sagittal spine types in a group of young patients ( $<25$ years) with lumbar disc herniation that underwent discectomy surgery. The results from the observed group are also compared to the normal population according to Roussouly et al. [15]. The spinal alignment types were determined by preoperative radiologic examinations. To our knowledge, this has not been investigated previously.

\section{Material and Methods}

\subsection{Study Population}

All 53 patients $<25$ years of age of both genders who had undergone Disc Herniation (DH) surgery at the Sahlgrenska University Hospital during 2004-2012 were retrospectively included in the study. The age limitations was set to reduce age related confounders such as anatomical changes and degeneration.

\subsection{Radiological Examination}

Fifty-one patients were examined with preoperative supine Magnetic Resonance Imag- 
ing (MRI) and two with supine Computer Tomography (CT). One patient was examined both with supine MRI and CT preoperatively. Eight patients were examined with both supine MRI and plain X-rays in the standing position preoperatively.

\subsection{Study Protocol}

All available preoperative radiological examinations were used to classify lumbar sagittal spinal type of each spine. Findings of scoliosis, transitional transverse processes, level of disc herniation or herniations, lumbo-sacral anomalies and spondylolisthesis were also registered.

The spines were classified in four different sagittal types according to Roussouly et al. [15]; a long thoracic kyphosis, a flat back, a normal sagittal spine and an increased thoracic kyphosis. These four types are similar to the Roussouly spinal alignment types with the difference that in the present study the majority ( 45 cases) were graded by horizontal radiological examinations and not with the vertical radiological examinations used in the Roussouly typing. In eight patients the grading was made on both standing $\mathrm{X}$-rays and supine MRI.

Classification of the lumbar type was performed by three senior spine surgeons independently. If consensus was not obtained independently, a re-test was performed followed by a discussion to reach consensus.

Medical charts were used to collect data on baseline characteristics, preoperative clinical findings, symptoms (low back pain, radiating leg pain/sciatica) and activity level (earlier and/or on-going activity in organized sports).

\subsection{Statistics}

Data were statistically described in terms of mean and standard deviation (SD), median and range, or frequencies and percentage when appropriate. To compare two sample proportions, observed group vs normal population, the 2-sample z-test was performed. All tests were two-sided, and significance was set at $\mathrm{p}<0.05$ for each test. The analyses were carried out using SPSS (IBM SPSS Statistics for Windows, Version 22.0. Armonk, NY: IBM Corp.).

\subsection{Ethical Statement}

This study is a non-intervention retrospective observational cross sectional register and journal study. The information regarding the patients was retrieved through the Swe Spine Register (Swedish spinal register) and medical charts. All patients had given consent to be included in the Swedish Spine Register and research linked to the register. All patients were radiologically examined by normal standard clinical pre-operative protocol.

\section{Results}

\subsection{Baseline Characteristics}

The mean age for the whole group was 18.1 years (range 12 to 24$)$ and $31(58 \%)$ were 
males and 22 (42\%) females. All patients (53/53) experienced radiating leg pain or sciatica preoperatively. Thirty-four patients (64\%) reported back pain. Fourteen patients (26\%) had no back pain and for five patients (9\%) the information was insufficient regarding back pain. The distribution of operated levels was L3 - L4, 1 patient (2\%), L4 L5, 25 patients (47\%), L5 - S1, 22 patients (42\%) and L4 - L5 + L5 - S1, 5 patients (9\%). Out of the total cohort four patients had transitional L5 (8\%). Three patients had transitional S1 vertebrae (6\%). Seven patients had scoliosis (13\%).

Twenty-six patients (49\%) were active in organized sports such as soccer, track and field and handball. Twenty-one patients (40\%) were not active in any organized sport activities. For six patients (11\%) there was no information regarding sport activity. Of the patients that were active in organized sport activities, twenty-one patients (81\%) were unable to participate in sports preoperative due to the symptomatic $\mathrm{DH}$ while five patients (19\%) were able to continue to participate in sport activities.

\subsection{Classification of Spine Type}

In 50 out of 53 patient spinal type classifications reached consensus independently. In three cases consensus was obtained after discussion by the three surgeons.

Classification of the patients spine demonstrated a long thoraco-lumbar kyphosis (Type 1) in 17\% (9 patients), a flat back (Type 2) in 62\% (33 patients), a normal sagittal alignment (Type 3) in 17\% (9 patients) and an increased thoracic kyphosis (Type 4) in $4 \%$ ( 2 patients) respectively (Table 1 ). There is no difference in the classification between MRI and X-ray examinations in the eight patients that were examined in both supine and standing position preoperatively (Figure 2 and Figure 3 ).

\subsection{Correlation to the Normal Population}

When compared to the normal population according to Roussouly et al. [15], statistical

Table 1. Characteristics for total and spinal alignment Type 1 - 4 .

\begin{tabular}{cccccc}
\hline & Total & Type 1 & Type 2 & Type 3 & Type 4 \\
\hline Number of patients & $53(100 \%)$ & $9(17 \%)$ & $33(62 \%)$ & $9(17 \%)$ & $2(4 \%)$ \\
Back pain prior to surgery & $34(64 \%)$ & $5(55 \%)$ & $22(67 \%)$ & $6(67 \%)$ & $1(50 \%)$ \\
Mean age (range) & $18.1(12-24)$ & $18.6(15-24)$ & $18.7(12-23)$ & $18.2(14-22)$ & $17(16-18)$ \\
Op level L3 - 4 & $1(2 \%)$ & $0(0 \%)$ & $1(3 \%)$ & $0(0 \%)$ & $0(0 \%)$ \\
Op level L4 - 5 & $25(47 \%)$ & $3(33 \%)$ & $17(51 \%)$ & $3(33 \%)$ & $2(100 \%)$ \\
Op level L5 - S1 & $22(42 \%)$ & $6(67 \%)$ & $13(39 \%)$ & $3(33 \%)$ & $0(0 \%)$ \\
Op level L4 - L5 - S1 & $5(9 \%)$ & $0(0 \%)$ & $2(6 \%)$ & $3(33 \%)$ & $0(0 \%)$ \\
Sport participation & $26(49 \%)$ & $5(56 \%)$ & $18(55 \%)$ & $3(33 \%)$ & $0(0 \%)$ \\
\hline
\end{tabular}

$\%$ of group. 


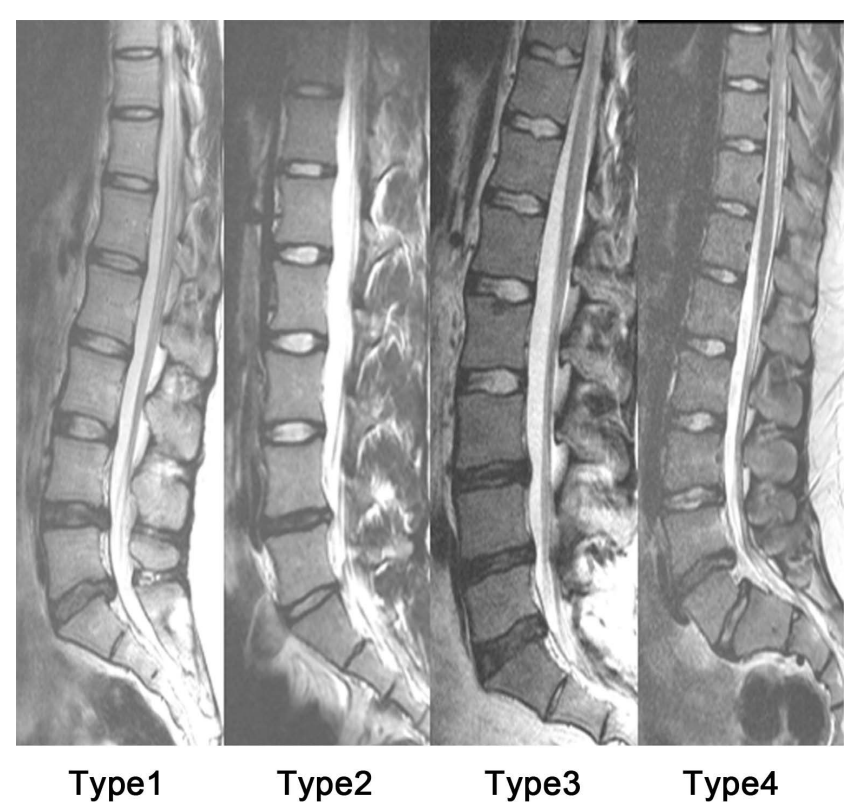

Figure 2. Sagittal spinal alignment Type 1 - 4 on supine MRI. MRI examinations showing the four groups of sagittal alignment of the spine in the study cohort.

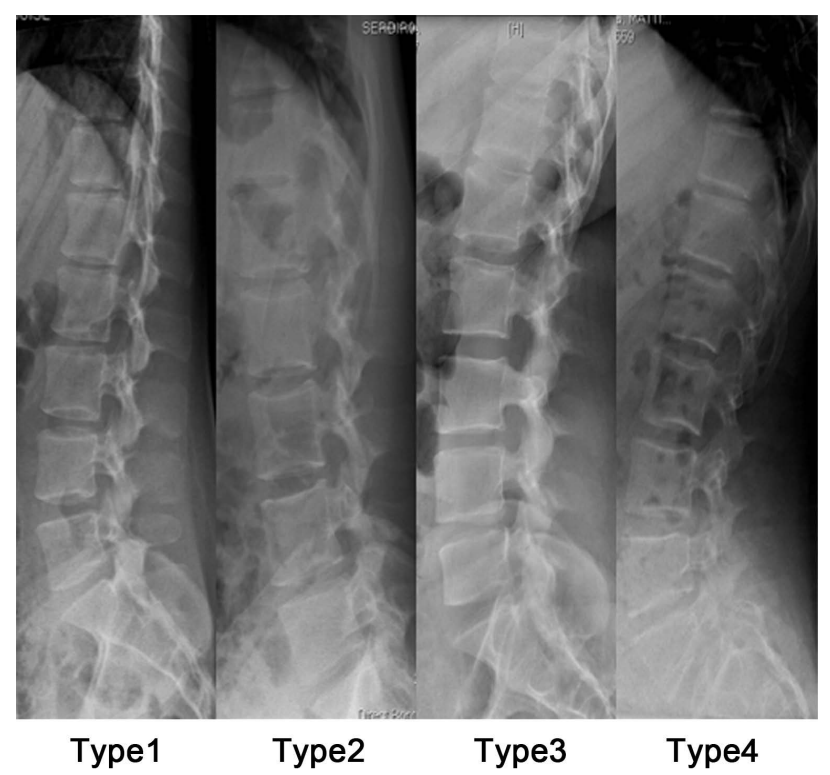

Figure 3. Sagittal spinal alignment Type 1 - 4 on standing X-ray. Standing X-rays showing the four groups of sagittal alignment of the spine in the study cohort. Eight patients had both X-ray and MRI examinations.

significant differences were found in spinal alignment Type 2 and 4 (Table 2 and Figure 4) in the present study. The study group displayed a much higher percentage of Type 2 compared to the normal population meanwhile a much less percentage of Type 4 .

No statistical difference could be observed in Type 1 and 3. 
Table 2. Observed group vs normal variation according to Roussouly et al. [15].

\begin{tabular}{cccc}
\hline Spinal alignment/Roussouly type & Observed (\%) & Normal population (\%) & P-value \\
\hline $\mathbf{1}$ & 17 & 21.3 & n.s. \\
2 & 62.2 & 11.3 & $<0.001$ \\
$\mathbf{3}$ & 17 & 37.5 & n.s. \\
$\mathbf{4}$ & 3.8 & 30 & $<0.001$ \\
\hline
\end{tabular}

Observed population $n=53$, and normal population $n=160$ described in p-value or in not significant $(>0.05)$. Chi-square test of proportions.

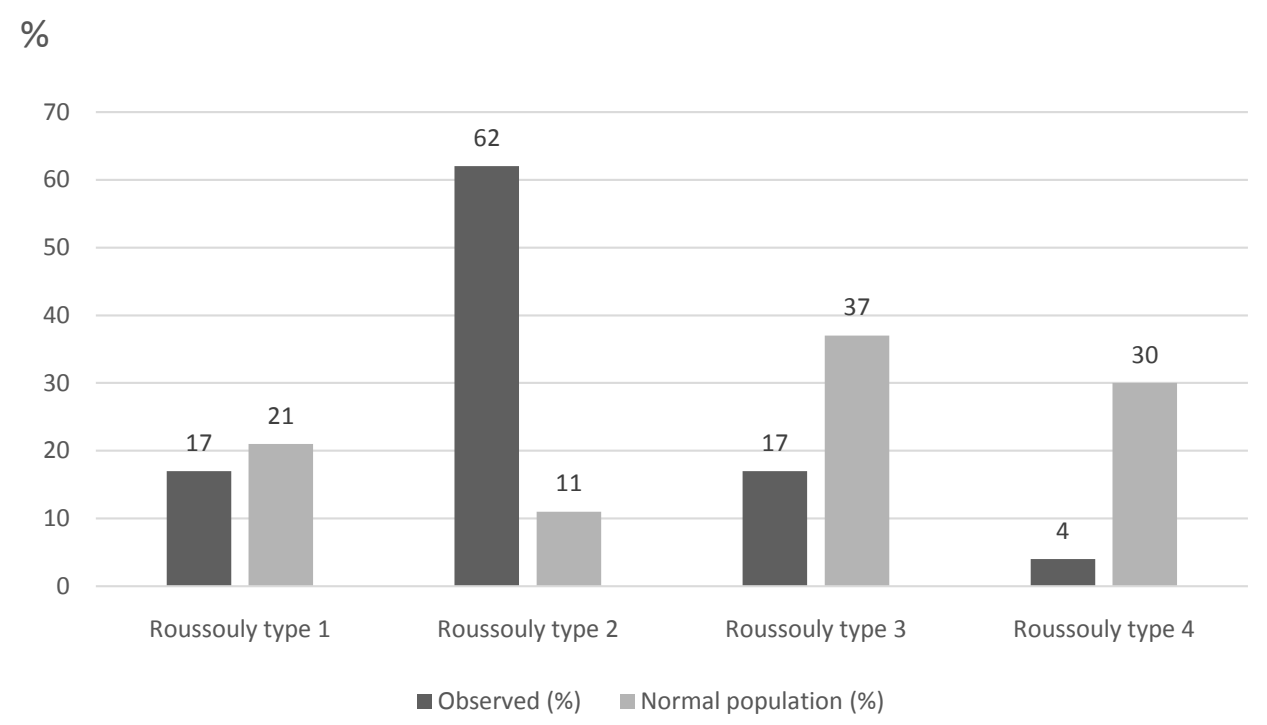

Figure 4. Observed group vs normal variation according to Roussouly et al. [15]. Sagittal spinal alignment type percentage comparison of observed group and normal population according to Roussouly et al. [15].

\section{Discussion}

The main finding in the present study was that $62 \%$ of the patients that underwent discectomy due to lumbar disc herniation were classified as having a flat back (Type 2), which is significantly higher when compared to the normal population according to Roussouly et al. [15]. These findings support the theory that a flat back and a straight spinal sagittal alignment is more likely to address maximum load on the lumbar disc and thereby creating central disc herniation in a young population.

Inter-rater validity was in this study high as 50 out 53 classifications reached blinded consensus between all three spine surgeons.

Pelvic incidence has been proven by several studies [9] [10] to be constant and is also a dominating factor to affect the lumbar lordosis through sacral slope. This suggests that radiology examinations display a stable morphology rather than a variable situation. The radiological examinations in this study were all in the horizontal plane. There is evidence that the alignment of the spine is not changed when comparing horizontal and vertical examinations. Several recent studies [1] [9] [10] [18] have demonstrated 
that the alignment of the thoraco-lumbar spine is dependent on the pelvic morphology. It is also well understood and presented by Marty et al. [5] that the spino-pelvic morphology alters during growth according to weight and pressure. Boulay et al. [9] have showed that many of the parameters that affect the alignment are not constant but are flexible such as pelvic retroversion and thoracic kyphosis. Pelvic incidence has though been proven to be constant and is also a dominating factor to affect the lumbar lordosis through the sacral slope.

If the lumbar lordosis is originated by spinal morphology or pelvic morphology is still unknown. The evidence supports a combined effect [9] [14]. There is a correlation between the pelvis, spine and also the hip joint through static morphology and compensatory mechanisms. Jonasson et al. [19] reported that top athletes in different sports had correlations between lumbar spine pain and hip joint pain. The study included a total of 75 ice-hockey players, divers, weight-lifters, wrestlers, orienteers and a control group who were assessed through a self-answered questionnaire regarding pain from joints and spine. Yoshimoto et al. [20] presented information that higher PI in younger individuals could be a reason for developing osteoarthritis of the hip in later life meanwhile lower PI was more common in patients with low back pain. The pelvic morphology could be the fundament that shapes the thoraco-lumbar curvature and the morphology of the hip joint. A speculation is that the correlation of spinal and hip pain could be described by reduced mobility in the hip as in femoro-acetabular impingement (FAI), affecting the spino-pelvic sagittal alignment and thereby the risk of lumbar back pain. The question still remains: is it the spine morphology that affects the pelvic and hip morphology or vice versa?

Disc herniations can possibly occur due to increased disc pressure by physical exercise. The increased disc pressure due to the morphology can be even greater in sports where extreme movements and stress are required [21] [22]. Cholewicki et al. [21] presented a study where the average load on the L3-L4 disc during competitive weight lifting was $>17,000 \mathrm{~N}$. In this study the patients with a spinal alignment Type 2, 55\% were active in organized sports, which was a similar frequency as in the patients with the other spinal alignment lumbar types. Theoretically, this may support the idea that patients with the highest risk of disc herniation in the lumbar spine are patients with a flat back and that this further increase with adding a high physical demands such as sports. It is well known that patients active in organized sports have higher risk of disc degeneration [23]-[26]. This may be developed by the same pathology as stated above.

\section{Limitations}

The main limitation of the present study was that the MRI examinations were all performed with the patient in the horizontal plane whereas the Roussouly classification system is based on examinations in erect position. In the present study there was no difference between the supine MRI and the standing radiographs regarding the type of sagittal alignment in the same patient. Future studies should exam this type of patients in erect positioning radiographs both pre-and postoperatively to be able to compare 
vertical and horizontal radiological examinations according to the spinal alignment.

Another limitation is that the distribution of curve types seen in this study could have been influenced by confounder such as low back pain due to the disc hernias. The present study included only patients that had undergone surgery due to symptomatic disc herniations in the lumbar spine. Lumbar types of asymptomatic patients or patients with a symptomatic disc herniation not undergoing surgery were not examined.

\section{Conclusion}

A majority of the patients (62\%) that underwent surgery due to herniated disc in the lumbar spine had a flat back and the distribution differed significantly compared to the normal population. More detailed and prospective studies are needed to increase the knowledge about to what extent different types of spino-pelvic sagittal alignment may influence the occurrence of thoraco-lumbar pathologies. Further, it is of great interest to explore if children/teenagers with certain spine types have increased risk for lumbar pathologies if practicing certain sports, which may influence recommendations on exercises for a growing spine.

\section{Acknowledgements}

The authors acknowledge the financial support of The Medical Society of Gothenburg, Sweden, Governmental grants under the ALF agreement, Anna and Edwin Berg's Foundation, Handlanden Hjalmar Svenssons Research Foundation and Doktor Felix Neuberghs Foundation.

\section{Competing Interests}

The authors have declared that no competing interests exist.

\section{Authors' Contributions}

OT carried out the data gathering, data analysis and is the main author of the manuscript. JB participated in data gathering and data analysis. $\mathrm{KH}, \mathrm{HB}$ and $\mathrm{AB}$ did the radiological assessment. $\mathrm{AB}$ created the study design and is the secondary author. All authors read and approved the final manuscript.

\section{References}

[1] Roussouly, P. and Pinheiro-Franco, J.L. (2011) Biomechanical Analysis of the Spino-Pelvic Organization and Adaptation in Pathology. European Spine Journal, 20, 609-618. http://dx.doi.org/10.1007/s00586-011-1928-x

[2] Roussouly, P., Berthonnaud, E. and Dimnet, J. (2003) [Geometrical and Mechanical Analysis of Lumbar Lordosis in an Asymptomatic Population: Proposed Classification]. Revue de Chirurgie Orthopedique et Reparatrice de L'appareil Moteur, 89, 632-639.

[3] Labelle, H., Roussouly, P., Berthonnaud, E., Transfeldt, E., O’Brien, M., Chopin, D., et al. (2004) Spondylolisthesis, Pelvic Incidence, and Spinopelvic Balance: A Correlation Study. Spine (Phila Pa 1976), 29, 2049-2054. http://dx.doi.org/10.1097/01.brs.0000138279.53439.cc

[4] Rajnics, P., Templier, A., Skalli, W., Lavaste, F. and Illes, T. (2002) The Importance of Spi- 
nopelvic Parameters in Patients with Lumbar Disc Lesions. International Orthopaedics, 26, 104-108. http://dx.doi.org/10.1007/s00264-001-0317-1

[5] Marty, C., Boisaubert, B., Descamps, H., Montigny, J.P., Hecquet, J., Legaye, J., et al. (2002) The Sagittal Anatomy of the Sacrum among Young Adults, Infants, and Spondylolisthesis Patients. European Spine Journal, 11, 119-125. http://dx.doi.org/10.1007/s00586-001-0349-7

[6] Yang, X., Kong, Q., Song, Y., Liu, L., Zeng, J. and Xing, R. (2014) The Characteristics of Spinopelvic Sagittal Alignment in Patients with Lumbar Disc Degenerative Diseases. European Spine Journal, 23, 569-575.

[7] Funao, H., Tsuji, T., Hosogane, N., Watanabe, K., Ishii, K., Nakamura, M., et al. (2012) Comparative Study of Spinopelvic Sagittal Alignment between Patients with and without Degenerative Spondylolisthesis. European Spine Journal, 21, 2181-2187.

http://dx.doi.org/10.1007/s00586-012-2374-0

[8] Mac-Thiong, J.M., Roussouly, P., Berthonnaud, E. and Guigui, P. (2011) Age- and SexRelated Variations in Sagittal Sacropelvic Morphology and Balance in Asymptomatic Adults. European Spine Journal, 20, 572-577. http://dx.doi.org/10.1007/s00586-011-1923-2

[9] Boulay, C., Tardieu, C., Hecquet, J., Benaim, C., Mouilleseaux, B., Marty, C., et al. (2006) Sagittal Alignment of Spine and Pelvis Regulated by Pelvic Incidence: Standard Values and Prediction of Lordosis. European Spine Journal, 15, 415-422. http://dx.doi.org/10.1007/s00586-005-0984-5

[10] Duval-Beaupere, G., Schmidt, C. and Cosson, P. (1992) A Barycentremetric Study of the Sagittal Shape of Spine and Pelvis: The Conditions Required for an Economic Standing Position. Annals of Biomedical Engineering, 20, 451-462. http://dx.doi.org/10.1007/BF02368136

[11] Kuntz, C.T., Shaffrey, C.I., Ondra, S.L., Durrani, A.A., Mummaneni, P.V., Levin, L.S., et al. (2008) Spinal Deformity: A New Classification Derived from Neutral Upright Spinal Alignment Measurements in Asymptomatic Juvenile, Adolescent, adult, and Geriatric Individuals. Neurosurgery, 63, 25-39.

[12] Mac-Thiong, J.M., Berthonnaud, E., Dimar, J.R., Betz, R.R. and Labelle, H. (2004) Sagittal Alignment of the Spine and Pelvis during Growth. Spine (Phila Pa 1976), 29, 1642-1647. http://dx.doi.org/10.1097/01.BRS.0000132312.78469.7B

[13] Mac-Thiong, J.M., Labelle, H., Berthonnaud, E., Betz, R.R. and Roussouly, P. (2007) Sagittal Spinopelvic Balance in Normal Children and Adolescents. European Spine Journal, 16, $227-$ 234. http://dx.doi.org/10.1007/s00586-005-0013-8

[14] Mac-Thiong, J.M., Labelle, H. and Roussouly, P. (2011) Pediatric Sagittal Alignment. European Spine Journal, 20, 586-590. http://dx.doi.org/10.1007/s00586-011-1925-0

[15] Roussouly, P., Gollogly, S., Berthonnaud, E. and Dimnet, J. (2005) Classification of the Normal Variation in the Sagittal Alignment of the Human Lumbar Spine and Pelvis in the Standing Position. Spine (Phila Pa 1976), 30, 346-353. http://dx.doi.org/10.1097/01.brs.0000152379.54463.65

[16] Barrey, C., Jund, J., Noseda, O. and Roussouly, P. (2007) Sagittal Balance of the Pelvis-Spine Complex and Lumbar Degenerative Diseases. A Comparative Study about 85 Cases. European Spine Journal, 16, 1459-1467. http://dx.doi.org/10.1007/s00586-006-0294-6

[17] Endo, K., Suzuki, H., Tanaka, H., Kang, Y. and Yamamoto, K. (2010) Sagittal Spinal Alignment in Patients with Lumbar Disc Herniation. European Spine Journal, 19, 435-438. http://dx.doi.org/10.1007/s00586-009-1240-1

[18] Li, W., Sun, Z., Guo, Z., Qi, Q., Kim, S.D., Zeng, Y., et al. (2013) Analysis of Spinopelvic Sa- 
gittal Alignment in Patients with Thoracic and Thoracolumbar Angular Kyphosis. Spine (Phila Pa 1976), 38, E813-E818. http://dx.doi.org/10.1097/BRS.0b013e3182913219

[19] Jonasson, P., Halldin, K., Karlsson, J., Thoreson, O., Hvannberg, J., Sward, L., et al. (2011) Prevalence of Joint-Related Pain in the Extremities and Spine in Five Groups of Top Athletes. Knee Surgery, Sports Traumatology, Arthroscopy, 19, 1540-1546.

http://dx.doi.org/10.1007/s00167-011-1539-4

[20] Yoshimoto, H., Sato, S., Masuda, T., Kanno, T., Shundo, M., Hyakumachi, T., et al. (2005) Spinopelvic Alignment in Patients with Osteoarthrosis of the Hip: A Radiographic Comparison to Patients with Low Back Pain. Spine (Phila Pa 1976), 30, 1650-1657. http://dx.doi.org/10.1097/01.brs.0000169446.69758.fa

[21] Cholewicki, J., McGill, S.M. and Norman, R.W. (1991) Lumbar Spine Loads during the Lifting of Extremely Heavy Weights. Medicine \& Science in Sports \& Exercise, 23, 11791186. http://dx.doi.org/10.1249/00005768-199110000-00012

[22] Cappozzo, A., Felici, F., Figura, F. and Gazzani, F. (1985) Lumbar Spine Loading during Half-Squat Exercises. Medicine \& Science in Sports \& Exercise, 17, 613-620. http://dx.doi.org/10.1249/00005768-198510000-00016

[23] Baranto, A., Hellstrom, M., Cederlund, C.G., Nyman, R. and Sward, L. (2009) Back Pain and MRI Changes in the Thoraco-Lumbar Spine of Top Athletes in Four Different Sports: A 15-Year Follow-Up Study. Knee Surgery, Sports Traumatology, Arthroscopy, 17, 11251134. http://dx.doi.org/10.1007/s00167-009-0767-3

[24] Baranto, A., Hellstrom, M., Nyman, R., Lundin, O. and Sward, L. (2006) Back Pain and Degenerative Abnormalities in the Spine of Young Elite Divers: A 5-Year Follow-Up Magnetic Resonance Imaging Study. Knee Surgery, Sports Traumatology, Arthroscopy, 14, 907 914. http://dx.doi.org/10.1007/s00167-005-0032-3

[25] Lundin, O., Hellstrom, M., Nilsson, I. and Sward, L. (2001) Back Pain and Radiological Changes in the Thoraco-Lumbar Spine of Athletes. A Long-Term Follow-Up. Scandinavian Journal of Medicine \& Science in Sports, 11, 103-109. http://dx.doi.org/10.1034/j.1600-0838.2001.011002103.x

[26] Sward, L., Hellstrom, M., Jacobsson, B., Nyman, R. and Peterson, L. (1991) Disc Degeneration and Associated Abnormalities of the Spine in Elite Gymnasts. A Magnetic Resonance Imaging Study. Spine (Phila Pa 1976), 16, 437-443.

http://dx.doi.org/10.1097/00007632-199104000-00009 
Submit or recommend next manuscript to SCIRP and we will provide best service for you:

Accepting pre-submission inquiries through Email, Facebook, LinkedIn, Twitter, etc. A wide selection of journals (inclusive of 9 subjects, more than 200 journals)

Providing 24-hour high-quality service

User-friendly online submission system

Fair and swift peer-review system

Efficient typesetting and proofreading procedure

Display of the result of downloads and visits, as well as the number of cited articles

Maximum dissemination of your research work

Submit your manuscript at: http://papersubmission.scirp.org/

Or contact ojo@scirp.org 